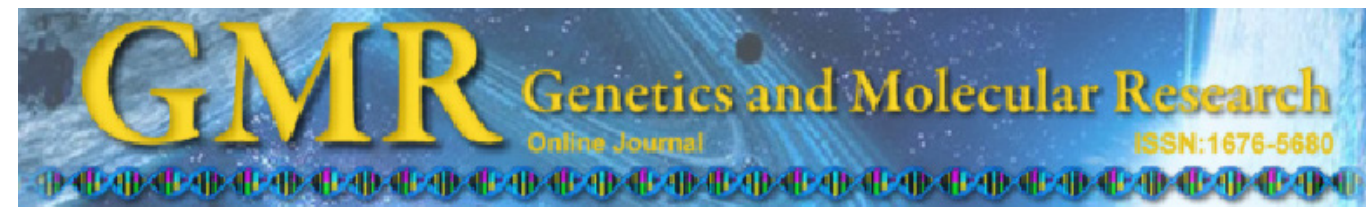

Research Article

\title{
Quaternary origin and genetic divergence of the endemic cactus Mammillaria pectinifera in a changing landscape in the Tehuacán Valley, Mexico
}

A. Cornejo-Romero ${ }^{1,4}$, J. Medina-Sánchez ${ }^{2}$, T. Hernández-Hernández ${ }^{3}$, B. Rendón-Aguilar ${ }^{4}$, P.L. Valverde ${ }^{4}$, A. Zavala-Hurtado ${ }^{4}$, S.P. Rivas-Arancibia ${ }^{5}$, M.A. Pérez-Hernández ${ }^{4}$, G. López-Ortega ${ }^{4}$, C. Jiménez-Sierra ${ }^{4}$ and C.F. Vargas-Mendoza ${ }^{6}$

${ }^{1}$ Doctorado en Ciencias Biológicas y de la Salud, Universidad Autónoma Metropolitana, D.F., México

${ }^{2}$ Department of Geography, University of Leicester, Leicester, United Kingdom ${ }^{3}$ Departamento de Biología Evolutiva, Instituto de Ecología A.C., Xalapa, Veracruz, México

${ }^{4}$ Departamento de Biología, Universidad Autónoma Metropolitana-Iztapalapa, D.F., México

${ }^{5}$ Escuela de Biología, Benemérita Universidad Autónoma de Puebla, Puebla, México

${ }^{6}$ Departamento de Zoología, Escuela Nacional de Ciencias Biológicas, Instituto Politécnico Nacional, D.F., México

Corresponding authors: B. Rendón-Aguilar / P.L. Valverde

E-mail: bra@xanum.uam.mx / plvp@xanum.uam.mx

Genet. Mol. Res. 13 (1): 73-88 (2014)

Received November 27, 2012

Accepted May 18, 2013

Published January 8, 2014

DOI http://dx.doi.org/10.4238/2014.January.8.6

ABSTRACT. The endemic Mexican cactus, Mammillaria pectinifera, shows low dispersal capabilities and isolated populations within the highly dissected landscape of Tehuacán Valley. These characteristics can restrict gene flow and act upon the genetic divergence and speciation in arid 
plants. We conducted a phylogeographic study to determine if the origin, current distribution, and genetic structure of $M$. pectinifera were driven by Quaternary geomorphic processes. Sequences of the plastids psbA-trnH and trnT-trnL obtained from 66 individuals from seven populations were used to estimate genetic diversity. Population differentiation was assessed by an analysis of molecular variance. We applied a stepwise phylogenetic calibration test to determine whether species origin and genetic divergence among haplotypes were temporally concordant with recognizable episodes of geomorphic evolution. The combination of plastid markers yielded six haplotypes, with high levels of haplotype diversity $(h=0.622)$ and low nucleotide diversity $(\pi=0.00085)$. The populations were found to be genetically structured $\left(F_{\mathrm{ST}}=0.682 ; \mathrm{P}<0.00001\right)$, indicating that geographic isolation and limited dispersal were the primary causes of genetic population differentiation. The estimated origin and divergence time among haplotypes were 0.017-2.39 and 0.019-1.237 mya, respectively, which correlates with Pleistocene tectonics and erosion events, supporting a hypothesis of geomorphically-driven geographical isolation. Based on a Bayesian skyline plot, these populations showed long term demographic stability, indicating that persistence in confined habitats has been the main response of this species to landscape changes. We conclude that the origin and haplotype divergence of $M$. pectinifera were a response to local Quaternary geomorphic evolution.

Key words: Genetic structure; Population isolation; Divergence time; Geomorphic evolution; Tehuacán Valley; Mammillaria pectinifera

\section{INTRODUCTION}

The remarkable plant diversification and speciation that gave rise to many modern dryland communities was the product of complex climatic and geologic phenomena that caused the well-documented Neogene global expansion of arid regions (Cowling et al., 2009; Arakaki et al., 2011). The rapid speciation of North and South American cacti has been related to the tectonic uplifting of orogenic belts that formed intricate landscapes and enhanced aridity due to rain shadow in some of the interior basins, creating a wide variety of new habitats that were successfully colonized by this group (Hershskovitz and Zimmer, 1997; Ritz et al., 2007). According to the estimated speciation rates and divergence times of the family Cactaceae based on molecular phylogeny, the radiation of Mexican cacti coincided with the tectonically driven Miocene-Pliocene expansion of arid environments (Hernández-Hernández, 2010). However, to date, there are no studies at the species level testing this idea and explaining the mechanisms by which the geomorphic deformations could produce geographical isolation, fragmentation, expansion, contraction, colonization and/or interruption of the gene flow that could lead to independent evolution of lineages, promoting the diversification of cacti. Under the general hypothesis that geomorphic evolution had been the main driver of cacti diversification, we present a phylogeographic analysis of the cactus Mammillaria pectinifera (Weber), in the northern sector of the Tehuacán Valley region (TVr).

The combination of a highly dynamic Cenozoic geologic history (Dávalos-Alvarez et al., 
2007), plus significant processes of diversification and speciation that have occurred in the TVr (Dávila et al., 2002), provide an ideal system for reconstructing the phylogeographic trends of plant species. This $10,000 \mathrm{~km}^{2}$ semi-arid region hosts 10 to $14 \%$ of the modern Mexican flowering plants and stands out as a main center of diversification and endemism of the family Cactaceae (Dávila et al., 2002). Within this family, the genus Mammillaria is represented by 16 endemic species, all adapted to the mosaic-like arrangement of specific habitats of TVr (Peters, 2000). The fact that the patchy distribution of $M$. pectinifera coincides almost exclusively with one particular type of landform strongly suggests that the current distribution and genetic features of this species have been shaped by the same long-term geomorphic processes that have transformed the physical landscape.

After the rise of the "Sierra Madre del Sur" highlands, continuous Cenozoic tectonic activity formed a series of intramontane basins, enhancing the local aridity since the Eocene (BeraldiCampesi et al., 2006). Further activity of the Oaxaca and Caltepec and other minor faults during most of the Cenozoic widened the valley zones, formed other minor basins and interrupted the topographic continuum of some highland chains, resulting in a variety of micro-environments within this semi-arid region. Most importantly, tectonic, volcanic and erosive geomorphic processes have been actively affecting the regional landscape as recently as the Holocene (Medina-Sánchez, 2010).

M. pectinifera was used as a model to study the conditions related to cactus diversification, because it shows isolated populations within the highly dissected TVr landscape and because it shows limited dispersal. It is known that when combined, these characteristics can restrict gene flow, acting as a driving force for genetic divergence and speciation in arid lands (Ellis et al., 2006). The species grows exclusively at 1778 to $2130 \mathrm{~m}$ a.s.l. on plateaus with very gentle slopes (ZavalaHurtado and Valverde, 2003). Populations are distributed in the northern sector of the TVr, and separated by 3.66 to $62.68 \mathrm{~km}$ (Valverde and Zavala-Hurtado, 2006). Pollination is carried out by small insects (Valverde PL, unpublished results), and seeds can be retained several years within mature fruits limiting dispersal in space and time (Peters et al., 2009). To date, there have been no attempts to explain the processes responsible for the diversification of mammillarias in the TVr.

Some of the likely consequences of the Quaternary geomorphic change on M. pectinifera could have been an irreversible isolation of its populations to restricted habitats and the formation of geographical barriers that prevented gene flow. At the molecular level, the interruption of gene flow would have resulted in populations of $M$. pectinifera showing different and geographically structured haplotype lineages, as well as high haplotype differentiation. We tested these hypotheses by using the chloroplast DNA (cpDNA) intergenic sequences trnT-trnL and $p s b A$-trnH to infer if: a) the landscape evolution of the TVr influenced the phylogeographical structure of $M$. pectinifera, b) if its populations experienced demographic historical changes, and c) if there is a temporal correspondence between the origin of M. pectinifera and its haplotypes and the Pleistocene geomorphic processes.

\section{MATERIAL AND METHODS}

\section{Study species}

M. pectinifera is a rare and endemic globose cactus (Bravo-Hollis and Sánchez-Mejorada, 1991), whose rarity is due to high habitat specificity, restricted geographical distribution and small population sizes (Zavala-Hurtado and Valverde, 2003). The main environmental variables that define the high habitat specificity of M. pectinifera, besides altitude and limestone summit plateaus, include 
xerophytic communities with relatively low species richness and coverage; high stoniness and shallow, sandy loam soil with relatively low organic matter and basic $\mathrm{pH}$ (Table 1; Zavala-Hurtado and Valverde, 2003; Zavala-Hurtado A, unpublished results). These environmental variables are similar among populations, particularly soil characteristics, supporting field observations of the strong association between Mammillaria species and edaphic characteristics (Peters, 2000). The xenogamic nature of $M$. pectinifera (determined from $\mathrm{O} / \mathrm{P}$ ratios and OIC index) imposes a strong dependency on bees and flies for pollen dispersal (Valverde PL, unpublished results) and consequently restricts gene flow to relatively short distances. Mature fruits and seeds can be retained within the maternal plant for several years, a phenomenon known as serotiny. Seeds are only released during episodes of high precipitation, increasing the chances of germination and establishment (Peters et al., 2009). Pollination by small insects, serotiny, and gravity dispersal can strongly limit pollen and seed mobility among populations, constraining genetic interchange. M. pectinifera populations are under serious extinction risk due to livestock, human activities and habitat deterioration, as well as illegal trade (Table 1; Valverde et al. 2009). Although this species is included in CITES Appendix I (2013) and the Red List of IUCN (2013), it must also be granted in the extinction risk category by the Mexican environmental laws for wild species protection (Semarnat, 2002), as suggested recently (Valverde et al., 2009).

Table 1. Population, population code, key shared environmental factors and disturbance index $\left(\mathrm{DI}_{\mathrm{R}}\right)$ of the populations studied of Mammillaria pectinifera.

\begin{tabular}{|c|c|c|c|c|c|c|c|c|c|c|c|c|c|}
\hline Population & $\begin{array}{l}\text { Population } \\
\text { code }\end{array}$ & $\begin{array}{l}\text { Altitude } \\
\text { (m a.s.l.) }\end{array}$ & $\begin{array}{c}\text { Slope } \\
\left({ }^{\circ}\right)\end{array}$ & $\begin{array}{c}\text { Stone } \\
\text { content (\%) }\end{array}$ & $\begin{array}{l}\text { Sand } \\
(\%)\end{array}$ & $\begin{array}{l}\text { Silt } \\
(\%)\end{array}$ & $\begin{array}{l}\text { Clay } \\
(\%)\end{array}$ & $\begin{array}{l}\text { Soil } \\
\text { texture }\end{array}$ & $\begin{array}{c}\text { Deep } \\
\text { soil }(\mathrm{cm})\end{array}$ & $\begin{array}{c}\text { Organic } \\
\text { matter }\end{array}$ & $\mathrm{pH}$ & $\begin{array}{c}\text { Vegetative } \\
\text { coverage (\%) }\end{array}$ & $\mathrm{DI}_{\mathrm{R}}$ \\
\hline Coapan & $\mathrm{COA}$ & 1778 & 5.0 & 40.0 & 50.4 & 33.8 & 15.8 & Sandy loam & 3.4 & 4.6 & 8.0 & 35.0 & 91.11 \\
\hline Texcala & TEX & 1914 & 19.0 & 73.0 & 55.1 & 36.9 & 8 & Sandy loam & 2.7 & 11.7 & 7.9 & 30.0 & 52.19 \\
\hline El Riego & RIE & 1950 & 10.0 & 68.3 & 56.75 & 35.4 & 7.9 & Sandy loam & 6.8 & 13.8 & 7.7 & 60.0 & 21.21 \\
\hline Frontera & FRON & 1950 & 10.0 & 61.7 & 63.1 & 28.9 & 8 & Sandy loam & 4.1 & 7.3 & 8.0 & 73.0 & 0.39 \\
\hline Tecamachalco & TECA & 2070 & 20.0 & 9.0 & 46.4 & 46.8 & 6.8 & Sandy loam & 5.8 & 2.9 & 7.7 & 20.0 & 100 \\
\hline Teteletitlan & TETE & 2100 & 15.0 & 77.0 & 66.2 & 29 & 4.8 & Sandy loam & 7.5 & 13.1 & 7.8 & 30.0 & 39.64 \\
\hline Zapotitlan & ZAP & 2110 & 12.0 & 75.0 & 47.4 & 39.7 & 13.0 & Sandy loam & 7.1 & 9.7 & 7.9 & 60.0 & 0.0 \\
\hline
\end{tabular}

Soil samples $(\mathrm{N}=2)$ were analyzed commercially. All other variables were measured in the field. Disturbance index $\left(D I_{R}\right)$ is an estimate of three disturbance agents: livestock, human activities and habitat deterioration. It ranges from no impact (0.0) to the highest recorded impact (100.0) according to Valverde et al. (2009).

\section{Study site}

The study was carried out on the northern part of the TVr, which encompasses part of the Puebla and Oaxaca states in Central Mexico (Figure 1A). Most of the known populations are within the Tehuacán-Cuicatlán Biosphere Reserve polygon. The seven populations studied are spatially segregated and cover all the distribution range of the species (Figure 1A). Climate in the TVr is semi-arid according to Koppen's classification [BSOhw" $(\mathrm{w})(\mathrm{e})(\mathrm{g})]$. Most rain falls in early summer (May and June) and early autumn (September) with an annual average precipitation of $380 \mathrm{~mm}$ and mean annual temperature of $21^{\circ} \mathrm{C}$ (García, 1973).

\section{Sampling, DNA extraction, amplification, and sequencing}

A total of 98 individuals of $M$. pectinifera from the seven populations were included in the present study. Populations were labeled Coapan (COA), Texcala (TEX), El Riego (RIE), 
Frontera (FRON), Tecamachalco (TECA), Teteletitlán (TETE) and Zapotitlán (ZAP) (Table 1, Figure 1A). Due to the risk of illegal extraction, geographic coordinates of the populations are not reported here. Approximately $100 \mathrm{mg}$ fresh vegetative tissue were collected from each individual, frozen in liquid nitrogen and stored at $-80^{\circ} \mathrm{C}$.

Total genomic DNA was isolated from the stem tissue using the DNeasy Plant Mini kit (Qiagen, Valencia, CA, USA) protocol. Two gene cpDNA non-coding regions were amplified and sequenced using the $p s b A-t r n H$ primers reported by Butterworth and Wallace (2004), and the trnT-trnL using universal $a$ and $b$ primers described by Taberlet et al. (1991). PCR was carried out in a total volume of $25 \mu \mathrm{L}$ containing $10 \mathrm{ng}$ genomic DNA, $0.5 \mathrm{U} / \mu \mathrm{L}$ Taq polymerase (Invitrogen Carlsbad, CA, USA), 1 X PCR buffer, $0.2 \mathrm{mM}$ dNTPs, $10 \mathrm{pM}$ each primer, and 2 $\mathrm{mM} \mathrm{MgCl}{ }_{2}$ for the $p s b A$-trnH region. For the trnT-trnL region the same protocol was followed, except for $14 \mathrm{pM}$ each primer and $1.75 \mathrm{mM} \mathrm{MgCl}_{2}$. PCR products were checked on $0.8 \%(\mathrm{w} / \mathrm{v})$ gels and cleaned using the QIAquick PCR Purification kit (Qiagen) or Montage PCR Centrifugal Filter Devices (Millipore, Darmstadt, Germany). The purified amplicons were sequenced in both directions with an ABI Prism Avant 3100 Genetic Analyzer (Applied Biosystems, Foster City, CA, USA) using the standard methods for the Big Dye Terminator Cycle Sequencing Ready Reaction kit (Applied Biosystems). Sequences were assembled and edited using SEQUENCHER 4.8 (Gene Codes Corporation, 2008) and alignment in MEGA 5.05 (Tamura et al., 2011). The chloroplast intergenic spacers were sequenced for only 66 individuals from the seven populations. The nucleotide sequences of derived haplotypes were deposited in the GenBank database with accession numbers JX974817, JX974818, JX974819 and JX974820 for the trnT-trnL region and JX974821, JX974822, JX974823 and JX974824 for the psbA-trnH region.

\section{Data analysis}

\section{Genetic diversity and structure}

Standard diversity indices were calculated at the species and population levels. Haplotype diversity $(h)$ and nucleotide diversity $(\pi)$ were obtained using the DnaSP 5 software (Librado and Rozas, 2009). The mean number of pairwise differences from the infinite-site equilibrium relationships $\left(\theta_{\pi}\right)$ was estimated using ARLEQUIN 3.11 (Excoffier et al., 2005).

To determine hierarchical population structure, an analysis of molecular variance (AMOVA) was performed using pairwise differences and haplotype frequencies with ARLEQUIN 3.11. Measures of DNA divergence between populations and groups $\left(F_{\mathrm{ST}}\right)$ were calculated, and the level of significance was tested using 1000 permutations.

\section{Demographic analysis}

Fu's $F_{s}$ statistic was calculated to test demographic expansion. A significantly large negative value for $F_{s}$ is expected in cases of population expansion. $F_{s}$ values were considered to be significant at $\mathrm{P} \leq 0.02$, which was calculated with DnaSP 5. The demographic history of $M$. pectinifera was inferred from the genealogy of cpDNA sequences using the Bayesian skyline plot (BSP) model, which estimates historical changes in effective population size, $N_{e}$. This model employs a Markov Chain Monte Carlo (MCMC) sampling procedure to estimate a posterior distribution of $N_{e}$ through time based on temporal distribution of coalescent events in gene genealogies, 
moving backwards from the present. This analysis was performed using the BEAST 1.6.1 software (Drummond et al., 2002-2011); with prior settings that included the GTR substitution model for $p s b A$-trnH and trnT-trn- $L$ regions and uncorrelated lognormal clock models with an estimated rate of nucleotide substitution of $\mu=1.0 \times 10^{-3}$ substitutions per neutral site per million years $(\mathrm{s} \cdot \mathrm{s}$ ${ }^{1} \cdot \mathrm{mya}^{-1}$ ), based on a comparison of eight chloroplast genes (Wolfe et al., 1987). Multiple replicates of MCMC were performed with 10 million steps with a burnin of $10 \%$, genealogies and parameters sampled every 1000 steps. The rest of the parameters were specified by default values. Finally, estimates of $N_{e} \mu$ and confidence intervals were calculated from the posterior probability distributions with TRACER 1.4.1(Rambaut and Drummond, 2003-2009) and summarized as a BSP.

\section{Phylogenetic analysis and divergence time estimations}

The phylogenetic relationships among $M$. pectinifera haplotypes were reconstructed under a Bayesian approach. This analysis was performed using a concatenated sequence dataset where all individuals with the same haplotype were considered as one. The jMODELTEST 0.1.1 software (Posada, 2008), set with the AIC criterion was used to select the best fit model of molecular evolution for each region. Selected models were HKY and GTR for the $p s b A$-trnH and trnT-trnL regions, respectively. Relationships among haplotypes were calculated using MrBAYES 3.2.1 (Ronquist and Huelsenbeck, 2003) with different partitions in each region. Two parallel MCMC were run simultaneously for $2 \times 10^{6}$ generations. We computed the 50\% majority rule consensus tree in MrBAYES 3.2.1 and used the Bayesian estimates of posterior probabilities to evaluate clade support.

To determine if the origin of M. pectinifera and its haplotypes could be related to the Plio/Pleistocene events occurring in the TVr (5.33-2.588 mya), we estimated the age origin of the species and the timing of haplotypes' divergence under a Bayesian approach as implemented in BEAST v 1.6.2. We used a stepwise approach. As a first step, we assembled a cpDNA sequence matrix for the Mammilloyd clade and used it to estimate the age of origin of M. pectinifera. This matrix was assembled with sequences obtained from GenBank. We used the matK-trnL region and psbA-trnH intergenetic spacer and the rpll6 intron sequences reported by Bárcenas et al. (2011) and Butterworth and Wallace (2004), and employed the sequences of Ferocactus robustus as the functional outgroup (accession numbers in Supplementary Data). With this dataset, we implemented an uncorrelated lognormal relaxed clock in BEAST 1.6.2 with a partitioned dataset, setting a GTR $+\mathrm{G}$ substitution model for each region based on the results of AIC comparisons from jMODELTEST 0.1.1. The Birth-Death speciation process was used to model the tree prior. We used a secondary calibration point obtained from a previous estimation of divergence of Cactaceae [Hernández-Hernández T, unpublished results; see also HernándezHernández (2010) for a preliminary dating analysis of Cactaceae]. We assigned a uniform age prior between 7.97 and 16.14 mya (million years ago) to constrain the crown Mammilloyd.

In a separate step of the dating analyses, and to determine the times when M. pectinifera haplotypes started to diverge, we performed a second estimation of divergence times for the $M$. pectinifera haplotypes with the trnT-trnL and $p s b A$-trnH concatenated matrix described previously. We implemented an uncorrelated lognormal relaxed clock in BEAST 1.6.2 with a partitioned dataset, selecting a coalescent model assuming constant population growth for the tree prior. To calibrate the root, we used the dates estimated for the divergence of M. pectinfiera derived from the previous step. For both divergence time estimations, we ran three independent $2^{8}$ and $5^{8}$ generation runs for the Mammiloyd and the M. pectinifera datasets, respectively. In both 
cases, the results were analyzed using TRACER 1.5 to assess convergence and effective sample sizes (ESS) for all parameters. In both cases, individual runs were combined using LogCombiner 1.6.1 (Drummond and Rambaut, 2007). Resulting dates were summarized in TreeAnnotator 1.6.1 (Drummond and Rambaut, 2007) by discharging a conservative 50\% of trees as burnin.

\section{RESULTS}

\section{Haplotype distribution, genetic diversity and structure}

Sequences of $p s b \mathrm{~A}-\operatorname{trn} \mathrm{H}$ and trnT-trnL ranged from 378 and $597 \mathrm{bp}$, respectively. The total length of the two combining fragments was $957 \mathrm{bp}$. Site mutations were detected at alignment positions $18,542,743$ and 918 . Insertion-deletion polymorphisms included single mononucleotide mutations. These mutations defined six haplotypes, which are shown in Figure 1B.

A

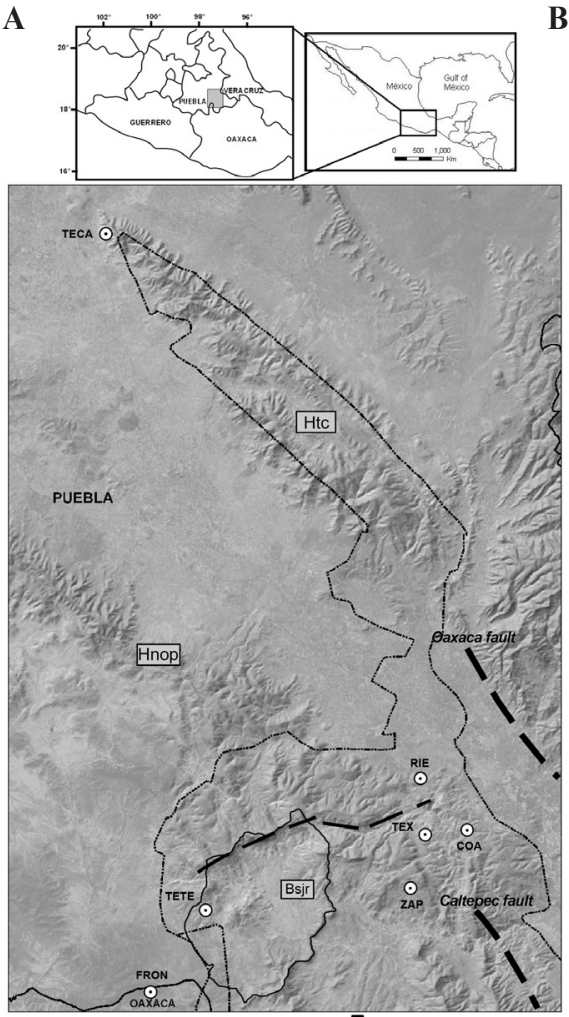

B

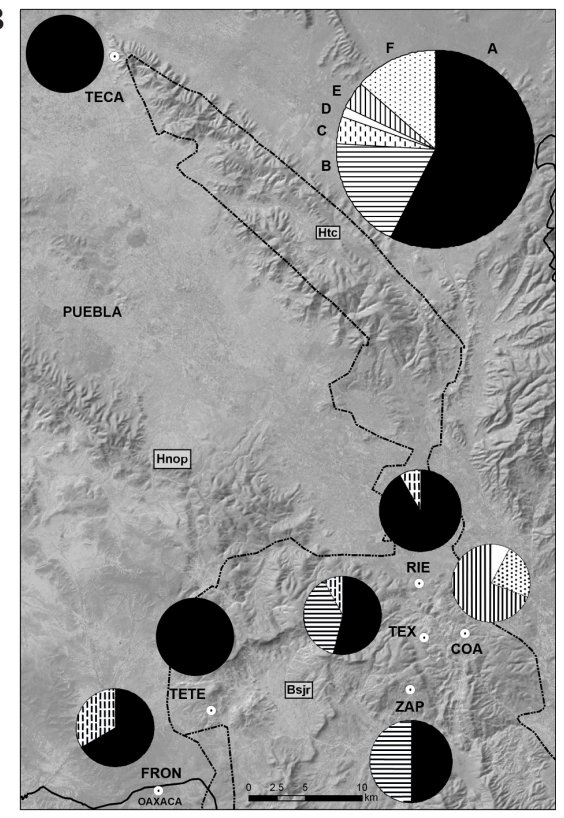

Figure 1. A. Approximate location of the seven populations of Mammillaria pectinifera under study and some tectonic faults mentioned in the text. B. Distribution and frequencies of the cpDNA haplotypes of Mammillaria pectinifera in the Tehuacán Valley region (TVr). Population names correspond to those listed in Table 1. Bsjr $=\mathrm{San}$ Juan Raya Basin; Htc = Cordon Tierra Colorada highlands; Hno = Cordon Nopala highlands. Dotted line encloses the TVr Biosphere Reserve; bold dashed lines show the Oaxaca and Caltepec faults, and thin dashed line shows associated minor faults at the northern sector of the TVr. Inner polygon enclosed by a continuous line represents Bsjr. These faults have shown activity until the Holocene and are considered likely major drivers of deformation of highlands and valleys across the distribution range of M. pectinifera in the northern sector of the TVr. 
The distribution and frequencies of cpDNA haplotypes defines a pattern of geographic structuring of the genetic variation (Figure 1B). The number of individuals carrying each haplotype varied from 1 to 38 . Haplotype $A$ was carried by $57.57 \%$ of all individuals sampled and had the widest distribution range, covering all populations except COA. Haplotype $B$ was detected only in TEX and ZAP with a frequency of $18.2 \%$. FRON, TEX and RIE shared haplotype $C$. Haplotypes $D, E$ and $F$ were exclusive of the COA population (Figure 1B).

Haplotype diversity $(h)$ was variable among populations and ranged from 0.000 in TECA and TETE to 0.667 in FRON with a total $h=0.622$ for all populations (Table 2). Nucleotide diversity $(\pi)$ was low in all populations indicating a few mutations among haplotypes. It ranged from 0.000 in the TECA and TETE to 0.0007 in TEX and FRON populations, and an overall of 0.00085 . The average value for pairwise differences at the species level was $\theta_{\pi}=$ 0.368 and differences among haplotypes within populations ranged from 0.167 to 0.667 . The lowest $\theta_{\pi}$ value was detected in RIE and the highest in TEX and FRON, as shown in Table 2.

Table 2. Population code, sample size (N), and standard genetic statistics of the populations studied of Mammillaria pectinifera. The haplotypes, number of individuals carrying each haplotype and the standard genetic statistics were based on $p s b A$-trnH and trnT-trnL intergenic sequences.

\begin{tabular}{|c|c|c|c|c|c|c|c|}
\hline Population code & $\mathrm{N}$ & Haplotypes & $h$ & $\pi$ & $\theta_{\pi}$ & $F_{s}$ & $\mathrm{P}$ \\
\hline $\mathrm{COA}$ & 14 & $\mathrm{D}(1), \mathrm{E}(3), \mathrm{F}(9)$ & $\begin{array}{c}0.500 \\
(0.136)\end{array}$ & $\begin{array}{c}0.00056 \\
(0.00018)\end{array}$ & $\begin{array}{c}0.538 \\
(0.534)\end{array}$ & -0.413 & 0.263 \\
\hline TEX & 15 & $\mathrm{~A}(7), \mathrm{B}(5), \mathrm{C}(1)$ & $\begin{array}{c}0.603 \\
(0.088)\end{array}$ & $\begin{array}{c}0.0007 \\
(0.00015)\end{array}$ & $\begin{array}{c}0.667 \\
(0.613)\end{array}$ & -0.021 & 0.295 \\
\hline RIE & 16 & $\mathrm{~A}(11), \mathrm{C}(1)$ & $\begin{array}{c}0.167 \\
(0.134)\end{array}$ & $\begin{array}{c}0.00017 \\
(0.00014)\end{array}$ & $\begin{array}{c}0.167 \\
(0.270)\end{array}$ & -0.476 & 0.310 \\
\hline FRON & 15 & $\mathrm{~A}(2), \mathrm{C}(1)$ & $\begin{array}{c}0.667 \\
(0.314)\end{array}$ & $\begin{array}{c}0.0007 \\
(0.0007)\end{array}$ & $\begin{array}{c}0.667 \\
(0.831)\end{array}$ & n.a. ${ }^{a}$ & n.a. \\
\hline TECA & 10 & $\mathrm{~A}(10)$ & 0.0000 & 0.0000 & - & n.a. & n.a. \\
\hline TETE & 14 & $\mathrm{~A}(1)$ & 0.0000 & 0.0000 & n.a. & n.a. & n.a. \\
\hline ZAP & 14 & $\mathrm{~A}(7), \mathrm{B}(7)$ & $\begin{array}{c}0.538 \\
(0.052)\end{array}$ & $\begin{array}{c}0.00056 \\
(0.00005)\end{array}$ & $\begin{array}{c}0.538 \\
(0.531)\end{array}$ & $\begin{array}{r}1.287 \\
-1.397\end{array}$ & $\begin{array}{l}0.370 \\
0.114\end{array}$ \\
\hline Total & 98 & 66 & $\begin{array}{c}0.622 \\
(0.055)\end{array}$ & $\begin{array}{l}0.00085 \\
(0.0000)\end{array}$ & $\begin{array}{c}0.368 \\
(0.397)\end{array}$ & & \\
\hline
\end{tabular}

Numbers among parenthesis represent standard error. $h=$ haplotype diversity; $\pi=$ nucleotide diversity; $\theta_{\pi}=$ mean number of pairwise differences from the infinite-site equilibrium; $F_{s}=$ neutrality test according to $\mathrm{Fu}(1997) ; \mathrm{P}=$ probability of neutrality test; ${ }^{\text {anot }}$ analyzed because of a lack of variation.

Genetic variation in M. pectinifera was structured geographically. AMOVA (Table 3 ) revealed that most of the total cpDNA variation $(68.19 \%, \mathrm{P}<0.00001)$ was explained by differences among populations, whereas a smaller fraction was found within populations $(31.81 \%)$.

\section{Historical demography}

$F_{s}$ values were not statistically significant, indicating no excess of recent mutations; thus, the hypothesis of population stasis was accepted. Values reported in Table 2 indicate that most of the populations sampled are currently not under expansion. BSP showed neither population expansion nor contraction of $M$. pectinifera since at least 0.25 mya. Effective population size showed a long-term stability, a pattern indicative of regional persistence (Figure 2). 


\begin{tabular}{|c|c|c|c|c|}
\hline Source of variation & d.f. & Sum of squares & Variance components & Percentage of variation \\
\hline Among populations & 6 & 25.44 & 0.447 & 68.19 \\
\hline Within populations & 59 & 12.31 & 0.208 & 31.81 \\
\hline Total & 65 & 37.76 & 0.656 & \\
\hline Fixation index $F_{\mathrm{ST}}$ & & & & \\
\hline
\end{tabular}

Levels of significance are based on 1023 random permutations. $\mathrm{P}<0.00001$.

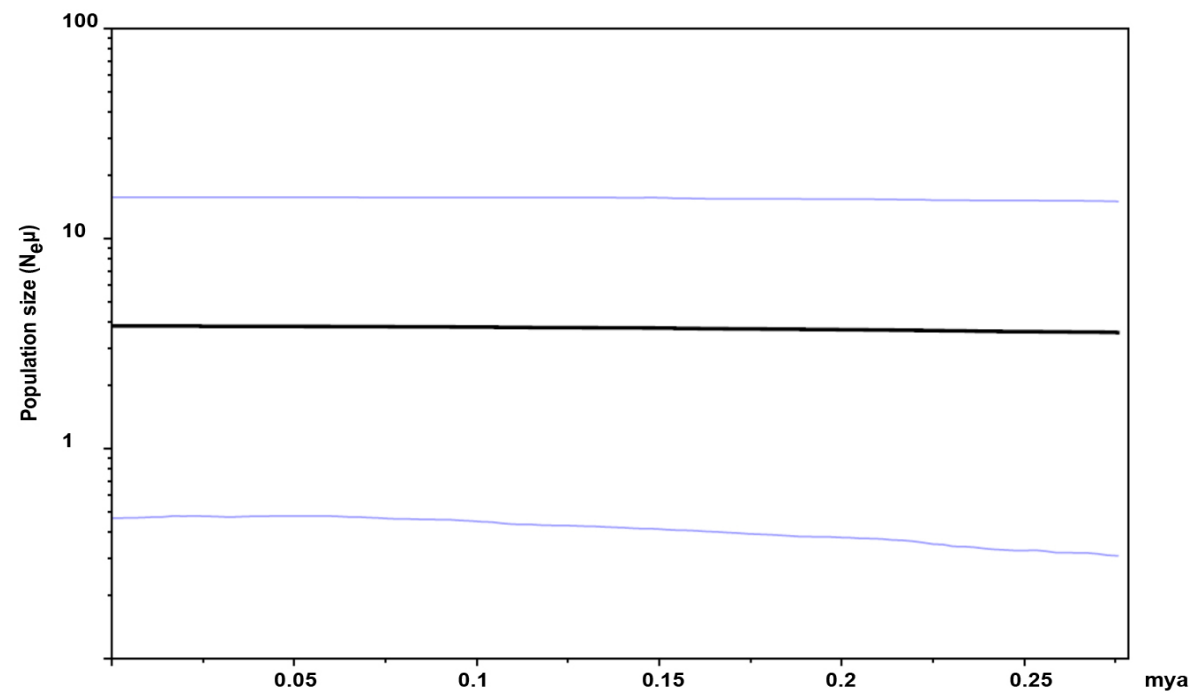

Figure 2. Bayesian skyline plot showed changes in population size of Mammillaria pectinifera through time (mutation per site). The black line represents the median estimate; gray line shows the $95 \%$ highest posterior density limits.

\section{Divergence times}

Divergence times estimation using Birth-Death speciation prior showed that $M$. pectinifera diverged from M. carmenae around 0.5878 mya [0.0172-2.3902 mya, $95 \%$ highest posterior density (HPD)], during Pleistocene (Figure 3A). Based on this result, M. carmenae was used as the outgroup of the M. pectinifera haplotypes, and a divergence time of 0.0172 2.3902 mya was set to calibrate the root. Under the coalescent model, M. pectinifera originated 0.1759 mya (0.019-1.237 mya, 95\% HPD), as shown in Figure 3B. The haplotypes $A, B$, $D$ and $F$ diverged from the ancestral clade formed by the $C$ and $E$ haplotypes at $c a .0 .0336$ mya (0.019-0.22639 mya, 95\% HPD), showing a very recent haplotype divergence time.

Haplotype relationships showed two poorly resolved clades (Figure 3B). The topology of the tree showed no correspondence with haplotype distribution. Haplotype $C$ is found in RIE, TEX and FRON, whereas haplotype $E$ is only present in COA. The second clade is form by $A, B, D$, and $F$ haplotypes, from which haplotype $A$ shows the widest distribution and frequency among populations and can represent the ancestral one of this clade.

Haplotype $B$ is found in ZAP and TEX, while $D$ and $F$ haplotypes are private of COA. 
This result can be related to a recent divergence and suggests that divergence occurred by geographic isolation and genetic drift.

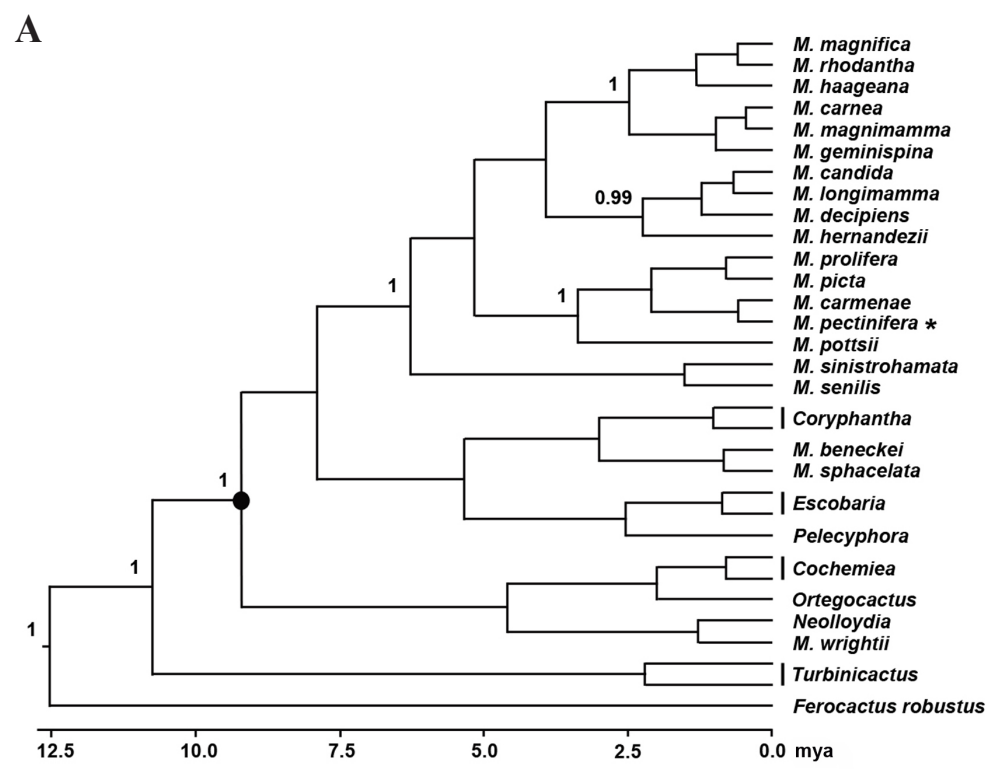

B

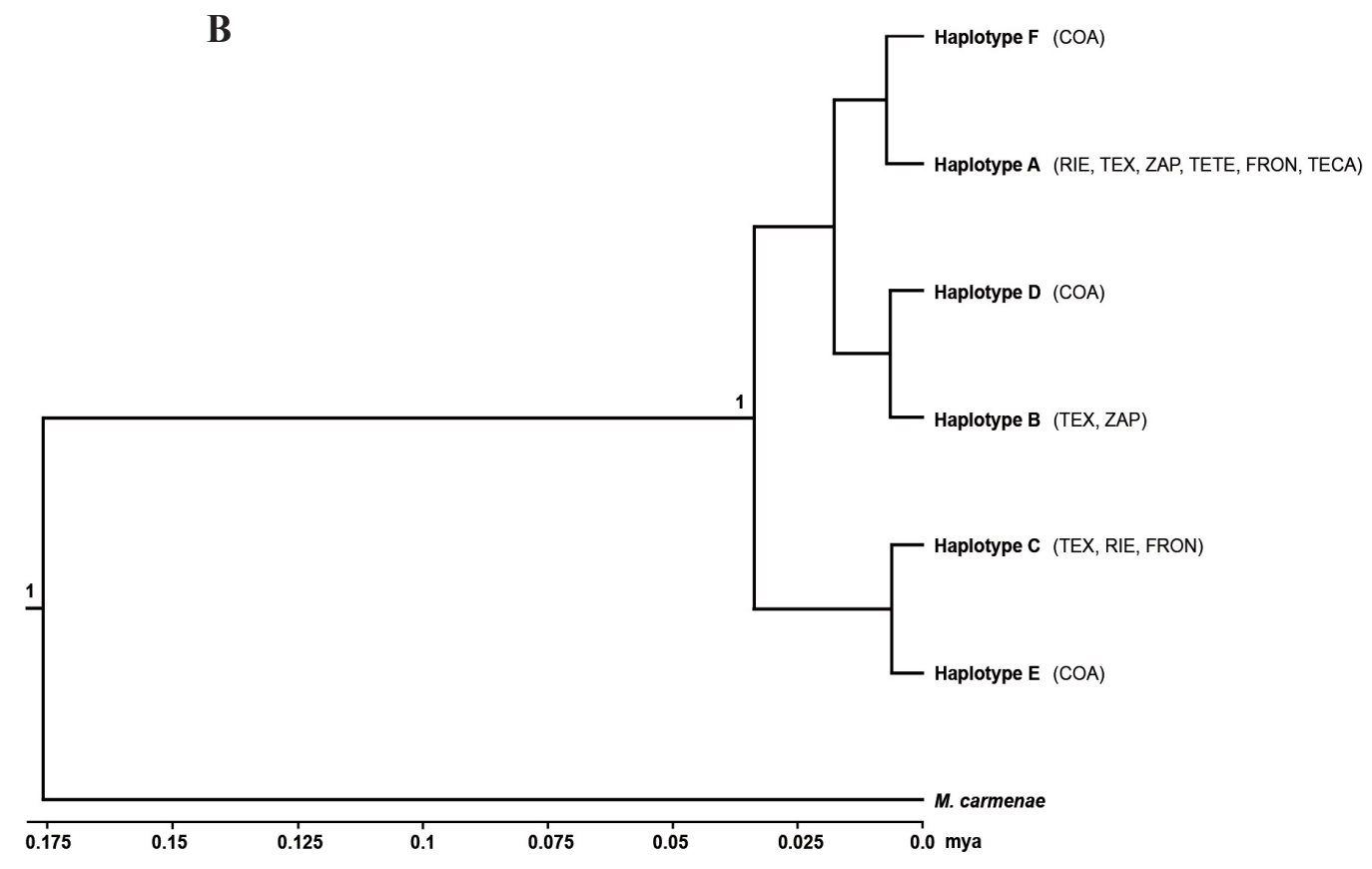

Figure 3. Chronograms based on a Bayesian approach. A. Mammilloyd clade. Filled circle shows the calibration point. B. Mammillaria pectinifera haplotypes. Numbers above branches denote posterior probabilities. 


\section{DISCUSSION}

The Pleistocene origin of $M$. pectinifera estimated through dating of the Mammilloyd clade [0.5878 $(0.0172-2.3902)$ mya] corresponds to the time when the broad structural geomorphology of the northern sector of the Tehuacán Valley was close to the current one (Dávalos-Alvarez et al., 2007), but was still experiencing significant erosional, alluvial and volcanic processes (Figure 3A; Medina-Sánchez, 2010). If this age is reliable, it is very likely that at that time, geomorphic changes, combined with the regional increase in aridity, produced new micro-habitats in some flat summits of the evolving highlands, creating suitable conditions for the appearance of $M$. pectinifera. The ability of these cacti to colonize successfully new drier conditions was due to their adaptations to high levels of water deficit, in a similar way to that described in other regions where coupled geomorphic-climatic changes have promoted divergence (Hershkovitz and Zimmer, 1997). However, our coalescence model showed that $M$. pectinifera diverged from $M$. carmenae more recently [0.1759 (0.019-1.237) mya]. It also shows that the haplotypes studied diverged during the Upper Pleistocene (0.126-0.0117 mya) (Figure. 3B). This earlier origin age could be related of the low nucleotide diversity detected from the trnT-trnL and $p s b A$-trnH regions. According to the dating of the Mammilloyd clade, based on three chloroplast regions and $3896 \mathrm{bp}$, other endemic species of the TVr, such as $M$. carnea, M. hernandezii and M. sphacelata, diverged earlier during the Pleistocene (Figure 3B), suggesting that the most realistic age of M. pectinifera correlates with that of its related species. An earlier date of origin (Upper Pleistocene) is difficult to reconcile with the timing and rate of the local geomorphic events that established the initial habitat conditions where M. pectinifera diverged. We believe that the tectonic and climatic changes during the Pliocene-Pleistocene transition can explain the formation of new habitats and the appearance of the species, whereas the volcanic, erosive, alluvial and the minor tectonic events that affected the area through the Quaternary better explain the divergence of the haplotypes.

Although a definite correspondence between the haplotype relationships and the geographical distribution of $M$. pectinifera could not be established due to low nucleotide variation, the divergence of the haplotypes could have occurred under population isolation. The analysis of variance revealed a strong population structure, suggesting a significant influence of landform evolution. Most of the variance was due to the variability among populations $\left(F_{\text {ST }}\right.$ $=0.682$ ) and was interpreted as a result of restricted gene flow imposed by the isolation and limited dispersion of the populations.

No other factor can account for the confinement of the populations to such specific habitats, and the concomitant limited gene flow and genetic differentiation, better than geomorphic evolution. Even though the modern distribution of the habitats that host $M$. pectinifera is clearly patchy, the geomorphological evidence suggests the presence of an environmental continuum during the early Quaternary. Following the regression of the Neogene lake that covered an important part of the Tehuacán basin (Dávalos-Alvarez et al., 2007), the soil conditions that characterize the upper flat highlands were probably shared by the intramontane valley areas that nowadays separate some of the populations. Widening of minor basins, pyroclastic deposits and alluvial valley fillings that characterized the Quaternary geology of the area (Dávalos-Alvarez et al., 2007; Medina-Sánchez, 2010) could have caused fragmentation of the primary environmental habitats and alteration of the original edaphic conditions, restricting M. pectinifera to isolated patches (Figure 1A).With the current 
knowledge on the geomorphic evolution of the region, it is possible to outline the history of the geographical isolation of the known populations of M. pectinifera.

The geographical and genetic isolation of TECA, the most distant population, was probably the outcome of the enormous amounts of volcanic ash erupted during the peaks of activity of some of the Trans Mexican Volcanic Belt structures located at distances on the order of tens of kilometers north of the study area. These pyroclastic products were deposited during the Pleistocene and covered vast valley areas in the northern part of the distribution range of the species, including the valley between Cordón Tierra Colorada (Htc) and Cordón Nopala (Hnop) highlands (Figure 1A). Notably, these thick deposits are not found in the stratigraphic records south of this valley, except for a thin layer of Holocene age south of the Nopala highlands (Medina-Sánchez, 2010), indicating that other geomorphic processes rather than volcanism and ash deposition governed the depositional dynamics below $18^{\circ} 30^{\prime}$ and were more significant in causing isolation of the rest of the populations.

The TETE population is found in a summit of the Cerro Gordo, which is a semi-conic mountain, relatively isolated from the Hnop (Figure 1A). The structure that divides Cerro Gordo from Hnop corresponds to a normal fault. The Pleistocene activity of this fault caused partial subsidence of the Cerro Gordo block relative to Hnop giving rise to the San Juan Raya basin (Bsjr; Medina-Sánchez, 2010). In this case, given the strong restrictions for seed dispersal, the opening of a small "v"-shaped basin between Cerro Gordo and Hnop could prevent gene flow. The Pleistocene tectonic activity that configured the geometry of the San Juan Raya basin could also explain the isolation of the FRON population. It is thought that this tectonic activity enhanced sediment release from Cerro Gordo and Hnop and promoted deposition in the valley zones that separate FRON from the rest (Medina-Sánchez, 2010). The presence of alluvial fillings covered by a thick calcrete (at least $1.5 \mathrm{~m}$ ) south of Cerro Gordo (MedinaSánchez, 2010), in what at present is the continental water divide, confirms significant sedimentary and geochemical alteration of the former soil that allowed M. pectinifera to expand its geographical range at least up to the area around FRON.

The populations COA, TEX, RIE and ZAP are also separated by small "v"-shaped basins without a defined valley area. Similar to the one formed between Cerro Gordo and Hnop, the shape and size of these basins indicate a recent formation. Considering that these populations are distributed within the influence zone of the Oaxaca and Caltepec faults (Figure 1A), two of the most active tectonic faults in the country, and the pre-existing geometry caused by the orogenic folding of the structures, it is likely that the formation of these basins was related to the localized erosion of intramontane depressions and/or to newly-formed fractures associated with tectonic activity. It has been documented that the Caltepec fault was very active during most of the Cenozoic, with traceable episodes as recently as the Holocene (ElíasHerrera et al., 2007). In particular, the activity of the Caltepec fault and/or associated faults could cause minor fracturing of the limestone highlands, initiating the processes of formation of these small basins.

The high number of haplotypes exclusive to COA could represent an extreme case of haplotype divergence under geographical isolation. The apparent independent evolution of this population can be the product of a longer period of isolation of this population, caused primarily by tectonic activity. The northward continuation of the Caltepec fault coincides with the alignment of faults that form the spatial separation of COA with respect to the other groups (Figure 1A). A similar pattern has been observed among populations of Eucalyptus caesia, in 
the southwest arid part of Australia (Byrne and Hopper, 2008). In that case, the granitic rocks that form the substrate, and hence the habitat for the species, have been weathered and fragmented since the Cretaceous.

On the other hand, the low seed and pollen dispersal capacity is an important ecological factor limiting gene flow, and at the same time increases the likelihood of the genetic drift to be a driving mechanism of population divergence. Gravity-dependent seed dispersal and serotiny constrain seedling recruitment to very local distances, preventing colonization of potential areas and promoting genetic divergence on a small geographical scale (Ellis et al., 2006). Even if seed dispersal to long distances can eventually occur, this has proven to be extremely rare. The case of $M$. pectinifera shows the predominant role of the evolution of the physical landscape on the genetic divergence of isolated populations, indicating that under a history of reduced gene flow, a strong genetic drift is the response mechanism shown by its populations. Other succulent plants that are shown to have experienced the same process belong to the African genus Argyroderma (Aizoaceae). These species show small but significant levels of genetic differentiation among populations, associated with long-term restrictions of gene flow, caused in turn by the confinement of the populations to quartz-rich soils, as well as to dispersal-limiting fruit retention by the mother plant (Ellis et al., 2006).

Our reconstruction of the historical demography indicates that at the population level $M$. pectinifera has persisted in highly specific habitats in response to geomorphic evolution. The BSP and demographic expansion analyses indicate that $M$. pectinifera has maintained populations historically stable. Low temporal and spatial seed dispersal capacity plus the high habitat specificity were probably the main functional causes of this habitat persistence. Population persistence has also been reported previously as a response mechanism to geo-climatic changes in arid environments. The cases of Acacia lobulata and E. caesia in Australia and Discorea biloba in Chile illustrate persistence in isolated regions or specific habitats with relative long-term stability (Byrne, 2008; Viruel et al., 2012). On the other hand, the demographic stability of $M$. pectinifera contrasts with the contraction and expansion pattern of refugia observed in desert plants of southwestern USA and northern Mexico in response to Pleistocene climatic instability (Rebernig et al., 2010).

The close relationships between the landscape structure (population isolation) and the genetic structure observed in the African species of Lithops and Argyroderma, support the idea that the limited gene flow and the edaphic and topographic heterogeneity of the landscape played a major role in species radiation (Ellis et al., 2006; Kellner et al., 2011). It has also been proven that morphological divergence is an alternative adaptive response to the edaphic complexity across different basins, constituting an important factor of species radiation. Under this scenario, local adaptation can be facilitated by limited gene flow. In the groups studied by Ellis et al. (2006), serotiny favored local dispersion, facilitating genetic divergence and adaptations to local habitats in fragmented geographies.

The present study showed that limited genetic flow imposed by the configuration of the landscape and the peculiar reproductive biology of $M$. pectinifera may have played a predominant role in the origin and genetic divergence of this plant species. Because most of the endemic species of Mammillaria in the TVr present a restricted spatial distribution, high habitat specificity related to altitudinal limits, soil and vegetation type (Peters, 2000), and since some of them show serotiny (M. hernandezii, M. napina and M. solisioides; Rodríguez-Ortega et al., 2006), it is likely that the genetic pattern described for M. pectinifera can be found in 
other related species. The confirmation of an extended pattern would provide additional support to the claim that geomorphological evolution was a crucial factor of diversification of the cacti in this region. It is also essential to carry out further studies on the role of natural selection in the diversification of this group. It is of particular interest to expand our understanding of the relative importance of individual components of the physical environment, such as soil conditions in promoting processes of local adaptation.

\section{CONCLUSIONS}

M. pectinifera originated during the Pleistocene. It shows a high genetic diversity, spatially structured and with haplotypes restricted or exclusive to some populations. The persistence of small populations in spatially-limited habitats has been the main response of the species to landscape evolution. Our results suggest that geomorphic evolution can play a determinant role in origin, haplotype divergence and speciation because of its indirect effect of restricting gene flow even over small geographical distances. It is essential to take this approach forward and to analyze the phylogeographic pattern of other species of Mammillaria endemic to the TVr to gain a better understanding of the mechanisms that lead to speciation within this tribe, which shows one of the highest speciation rates within the family Cactaceae.

Given the observed high haplotype diversity and its structure, as well as the divergence ages, it is crucial to highlight the importance of preserving and protecting the majority of the known wild populations and their environments to maintain the ongoing evolutionary processes that drive the diversification of this group. We urge the implementation of strategies to preserve in situ and ex situ most of the gene pool of the species, prioritizing the COA and TEX populations because of their high haplotype diversity and perhaps most importantly because of the high disturbance rates reported for their habitats.

\section{ACKNOWLEDGMENTS}

Research supported by CONACyT through the grant \#FOSEMARNAT-2004-01-26 and Apoyo Integral para la Formación de Doctores del CONACyT \#34903. Universidad Autónoma Metropolitana provided logistic support. ACR received support from CONACyT through the $\mathrm{PhD}$ grant \#158260. This paper is part of the graduate research study of A CornejoRomero, alumnus of Doctorado en Ciencias Biológicas y de la Salud at the Universidad Autónoma Metropolitana. Thanks are due to the following: Pedro G. Miranda Pacheco for field assistance; Monserrat Jiménez for field assistance and for editing figures; Gilberto Hernández for drawing the maps; Alejandra Serrato, Martha G. Rocha and Eduardo Delgadillo for laboratory assistance; Rosaura Grether for her valuable comments on the manuscript; and Caroline Berry for proofreading the English version.

\section{Supplementary material}

\section{REFERENCES}

Arakaki M, Christin PA, Nyffeler R, Lendel A, et al. (2011). Contemporaneous and recent radiations of the world's major succulent plant lineages. Proc. Natl. Acad. Sci. U. S. A. 108: 8379-8384.

Bárcenas RT, Yesson C and Hawkins JA (2011). Molecular systematics of the Cactaceae. Cladistics 27: 470-489. 
Beraldi-Campesi H, Cevallos-Ferriz SRS, Centeno-García E, Arenas-Abad C, et al. (2006). Sedimentology and paleoecology of an Eocene-Oligocene alluvial-lacustrine arid system, Southern Mexico. Sediment. Geol. 191: 227-254.

Bravo-Hollis H and Sánchez-Mejorada H (1991). Las Cactáceas de México. Vol.II. Universidad Nacional Autónoma de México, México, D.F.

Butterworth CA and Wallace RS (2004). Phylogenetic studies of Mammillaria (Cactaceae) - insights from chloroplast sequence variation and hypothesis testing using the parametric bootstrap. Am. J. Bot. 91: 1086-1098.

Byrne M and Hopper SD (2008). Granite outcrops as ancient islands in old landscapes: evidence from the phylogeography and population genetics of Eucalyptus caesia (Myrtaceae) in Western Australia. Biol. J. Linn. Soc. Lond. 93: 177-188.

CITES (Convention on International Trade in Endangered Species of Wild Flora and Fauna). (2013). Available at [http:// www.cites.org/eng/app/appendices.php]. Accessed November 11, 2013.

Cowling RM, Proches S and Partridge TC (2009). Explaining the uniqueness of the Cape flora: incorporating geomorphic evolution as a factor for explaining its diversification. Mol. Phylogenet. Evol. 51: 64-74.

Dávalos-Álvarez OG, Nieto-Samaniego AJ, Alaniz-Álvarez SA, Martínez-Hernández E, et al. (2007). Estratigrafía cenozoica de la región de Tehuacán y su relación con el sector norte de la falla de Oaxaca. Rev. Mex. Cien. Geol. 24: $197-215$.

Dávila P, Arizmendi MC, Valiente-Banuet A, Viseñor JL, et al. (2002). Biological diversity in the Tehuacán-Cuicatlán Valley, Mexico. Biodivers. Conserv. 11: 421-442.

Drummond AJ and Rambaut A (2007). BEAST: Bayesian evolutionary analysis by sampling trees. BMC Evol. Biol. 7 : 214.

Drummond AJ, Rambaut A and Suchard MA (2002-2011). Bayesian Evolutionary Analysis Sampling Trees Version v1.6.2. Available at [http://beast.bio.ed.ac.uk]. Accessed January 29, 2012.

Elías-Herrera M, Ortega-Gutiérrez F, Sánchez-Zavala JL, Macías-Romo C, et al. (2007). The Caltepec fault zone: Exposed roots of a long-lived tectonic boundary between two continental terranes of southern Mexico. Geol. Soc. Am. Special Paper 422: 317-342.

Ellis AG, Weis AE and Gaut BS (2006). Evolutionary radiation of "stone plants" in the genus Argyroderma (Aizoaceae): unraveling the effects of landscape, habitat, and flowering time. Evolution 6: 39-55.

Excoffier L, Laval G and Schneider S (2005). Arlequin (version 3.0): an integrated software package for population genetics data analysis. Evol. Bioinform. Online 1: 47-50.

Gene Codes Corporation (2008). Sequencher 4.8 Sequence Analysis Software, Gene Codes Corporation, Ann Arbor, MI, USA. Available at [http://www.genecodes.com]. Accessed March 2009.

García E (1973). Modificaciones al Sistema de Clasificación Climática de Köeppen. Instituto de Geografía. UNAM, Mexico, D.F.

Hernández-Hernández T (2010). Radiaciones Evolutivas de Linajes de Plantas Suculentas en el Orden Caryophyllales con Enfasis en la Familia Cactaceae. Doctoral thesis. Universidad Nacional Autónoma de México, Mexico, D.F.

Hershkovitz MA and Zimmer EZ (1997). On the evolutionary origins of the cacti. Taxon 46: 217-232.

IUCN 2013. The IUCN Red List of Threatened Species. Version 2013.1. Available at [http://www.iucnredlist.org]. Accessed November 11, 2013.

Kellner A, Ritz CM, Schlittenhardt P and Hellwig FH (2011). Genetic differentiation in the genus Lithops L. (Ruschioideae, Aizoaceae) reveals a high level of convergent evolution and reflects geographic distribution. Plant Biol. 13: 368-380.

Librado P and Rozas J (2009). DnaSP v5: a software for comprehensive analysis of DNA polymorphism data. Bioinformatics 25: 1451-1452.

Medina-Sánchez J (2010). Cenozoic Environmental Evolution of the San Juan Raya Basin, South-Central Mexico. PhD thesis. University of Leicester, Leicester.

Peters EM (2000). Conocimiento y Conservación de las Mamilarias Endémicas del Valle de Tehuacán-Cuicatlán. Consejo Nacional para el Conocimiento y uso de la Biodiversidad. CONABIO, México, D.F.

Peters EM, Martorell C and Ezcurra E (2009). The adaptive value of cued seed dispersal in desert plants: Seed retention and release in Mammillaria pectinifera (Cactaceae), a small globose cactus. Am. J. Bot. 96: 537-541.

Posada D (2008). jModelTest: phylogenetic model averaging. Mol. Biol Evol. 25: 1253-1256.

Rambaut A and Drummond AJ (2003-2009). TRACER v1.5.0 MCMC Tracer Analysis Tool. Institute for Evolutionary Biology, University of Edinburgh. Available at [http://tree.bio.ed.ac.uk/]. Accessed January 29, 2012.

Rebernig CA, Weiss-Schneeweiss H, Schneeweiss GM, Schönswetter P, et al. (2010). Quaternary range dynamics and polyploid evolution in an arid brushland plant species (Melampodium cinereum, Asteraceae). Mol. Phylogenet. Evol. 54: 594-606.

Ritz CM, Martins L, Mecklenburg R, Goremykin V, et al. (2007). The molecular phylogeny of Rebutia (Cactaceae) and its allies demonstrates the influence of paleogeography on the evolution of South American mountain cacti. Am. J. Bot. 94: 1321-1332. 
Rodríguez-Ortega C, Franco J and Mandujano MC (2006). Serotiny and seed germination in three threatened species of Mammillaria (Cactaceae). Basic Appl. Ecol. 7: 533-544.

Ronquist F and Huelsenbeck JP (2003). Mr. Bayes v3.1.2. Bayesian Analysis of Phylogeny. GNU General Public License, Boston.

Semarnat (Secretaria de Medio Ambiente y Recursos Naturales) (2002). Norma Oficial Mexicana NOM-059-ECOL-2001, Protección Ambiental-Especies Nativas de México de Flora y Fauna Silvestres-Categorías de Riesgo y Especificaciones para Su Inclusión, Exclusión o Cambio-Lista de Especies en Riesgo. Diario Oficial de la Federación., México, D.F.

Taberlet P, Gielly L, Pautou G and Bouvet J (1991). Universal primers for amplification of three non-coding regions of chloroplast DNA. Plant Mol. Biol. 17: 1105-1109.

Tamura K, Peterson D, Peterson N and Stecher G (2011). MEGA 5: Molecular Evolutionary Genetics Analysis using Maximum Likelihood, Evolutionary Distance, and Maximum Parsimony Methods. Mol. Biol. Evol. 24: 1596-1599.

Valverde PL and Zavala-Hurtado JA (2006). Assessing the ecological status of Mammillaria pectinifera Weber (Cactaceae), a rare and threatened species endemic of the Tehuacán-Cuicatlán Region in Central Mexico. J. Arid. Environ. 64: 193-208.

Valverde PL, Zavala-Hurtado JA, Jiménez-Sierra C, Rendón-Aguilar B, et al. (2009). Evaluación del riesgo de extinción de Mammillaria pectinifera, cactácea endémica de la Región de Tehuacán-Cuicatlán. Rev. Mex. Biodivers. 80: 219230.

Viruel J, Catalán P and Segarra-Moragues JG (2012). Disrupted phylogeographical microsatellite and chloroplast DNA patterns indicate a vicariance rather than long-distance dispersal origin for the disjunct distribution of the Chilean endemic Dioscorea biloba (Dioscoreaceae) around the Atacama Desert. J. Biogeogr. 39: 1073-1085.

Wolfe KH, Li WH and Sharp PM (1987). Rates of nucleotide substitution vary greatly among plant mitochondrial, chloroplast, and nuclear DNAs. Proc. Natl. Acad. Sci. U. S. A. 84: 9054-9058.

Zavala-Hurtado JA and Valverde PL (2003). Habitat restriction in Mammillaria pectinifera, a threatened endemic Mexican cactus. J. Veg. Sci. 14: 891-898. 